\title{
Association of genetic variants with dyslipidemia
}

\author{
SHINTARO ABE ${ }^{1}$, FUMITAKA TOKORO $^{1}$, REIKO MATSUOKA ${ }^{1}$, MASAZUMI ARAI $^{1}$, TOSHIYUKI NODA $^{1}$, \\ SACHIRO WATANABE ${ }^{1}$, HIDEKI HORIBE ${ }^{2}$, TETSUO FUJIMAKI ${ }^{3}$, MITSUTOSHI OGURI $^{4}$, \\ KIMIHIKO KATO $^{5}$, SHINYA MINATOGUCHI ${ }^{6}$ and YOSHIJI YAMADA ${ }^{7}$
}

\author{
${ }^{1}$ Department of Cardiology, Gifu Prefectural General Medical Center, Gifu, Gifu 500-8717; ${ }^{2}$ Department of Cardiovascular \\ Medicine, Gifu Prefectural Tajimi Hospital, Tajimi, Gifu 507-8522; ${ }^{3}$ Department of Cardiovascular Medicine, Inabe General \\ Hospital, Inabe, Mie 511-0428; ${ }^{4}$ Department of Cardiology, Japanese Red Cross Nagoya First Hospital, Nagoya, \\ Aichi 453-8511; ${ }^{5}$ Department of Internal Medicine, Meitoh Hospital, Nagoya, Aichi 465-0025; ${ }^{6}$ Department of \\ Cardiology, Gifu University Graduate School of Medicine, Gifu, Gifu 501-1194; ${ }^{7}$ Department of \\ Human Functional Genomics, Life Science Research Center, Mie University, Tsu, Mie 514-8507, Japan
}

Received September 22, 2014; Accepted June 6, 2015

DOI: $10.3892 / \mathrm{mmr} .2015 .4081$

\begin{abstract}
Although genetic variants, which regulate lipid metabolism, have been extensively investigated in Caucasian populations, the genes, which confer susceptibility to dyslipidemia in Japanese individuals, remain to be elucidated. The aim of the present study was to examine a possible association among hypertriglyceridemia, hypo-high density lipoprotein (HDL)-cholesterolemia or hyper-low density lipoprotein (LDL)-cholesterolemia in Japanese individuals with 29 polymorphisms observed to confer susceptibility for coronary heart disease. This was performed through meta-analyses of genome-wide association studies in Caucasian populations The study population comprised 2,354 individuals with dyslipidemia (hypertriglyceridemia, hypo-HDL-cholesterolemia or hyper-LDL-cholesterolemia) and 3,106 control individuals. To compensate for multiple comparisons of genotypes, a false discovery rate (FDR) of $<0.05$ was adopted to determine the statistical significance of the associations. Comparisons of allele frequencies using the $\chi^{2}$ test revealed that rs964184 of zinc finger gene $\left(Z P R 1 ; \mathrm{FDR}=2.1 \times 10^{-7}\right)$, rs4845625 of interleukin 6 receptor (IL6R; FDR=0.032), rs46522 of ubiquitin-conjugating enzyme E2Z gene (UBE2Z; FDR=0.032) and $\mathrm{rs} 17514846$ of furin $(\mathrm{FDR}=0.041)$ were significantly associated with hypertriglyceridemia. The $\chi^{2}$ test revealed that rs599839 of proline/serine-rich coiled-coil 1 (PSRC1; $\mathrm{FDR}=0.004)$ and rs2075650 of translocase of outer mitochondrial membrane 40 homolog $($ TOMM40; FDR=0.004) were
\end{abstract}

Correspondence to: Professor Yoshiji Yamada, Department of Human Functional Genomics, Life Science Research Center, Mie University, 1577 Kurima-machiya, Tsu, Mie 514-8507, Japan

E-mail: yamada@gene.mie-u.ac.jp

Key words: dyslipidemia, hypertriglyceridemia, hypo-high density lipoprotein-cholesterolemia, genetics, polymorphism, hyper-low density lipoprotein-cholesterolemia significantly associated with hyper-LDL-cholesterolemia. Multivariate logistic regression analysis with adjustment for age, gender and body mass index revealed that rs964184 of ZPR1 $\left(\mathrm{P}=5.1 \times 10^{-7}\right.$; odds ratio, 1.37; dominant model), rs4845625 of IL6R ( $\mathrm{P}=0.0019$, odds ratio, 1.25 ; dominant model) and rs46522 of $U B E 2 Z(\mathrm{P}=0.0039$, odds ratio, 1.19; dominant model) were significantly associated with hypertriglyceridemia, and that rs599839 of PSRC1 ( $\mathrm{P}=0.0004$, odds ratio, 0.70; dominant model) and rs2075650 of TOMM40 ( $\mathrm{P}=0.0004$, odds ratio, 1.43; dominant model) were significantly associated with hyper-LDL-cholesterolemia. Therefore, ZPRI, IL6R, and UBE2Z may be susceptibility loci for hypertriglyceridemia, whereas PSRC1 and TOMM4O may be such loci for hyper-LDL-cholesterolemia in Japanese individuals.

\section{Introduction}

Dyslipidemia is a complex and multifactorial disease caused by an interaction between genetic and environmental factors, the latter including a high-fat and high-calorie diet and physical inactivity. In conjunction with lifestyle and environmental factors, a genetic factor has been revealed to contribute to the development of this metabolic disorder $(1,2)$. Accordingly, recognizing the genetic susceptibility for dyslipidemia has become crucial to promote an improved assessment of disease prediction and allow an earlier preventive strategy to be implicated.

Genetic variants, which regulate lipid metabolism, have been extensively investigated and 157 loci associated with plasma lipid levels have been identified, including 62 loci, which have not been previously reported (3). At present, $>400$ genes have been postulated as potential candidates for dyslipidemia (4). It was previously identified that rs6929846 $(\mathrm{C} \rightarrow \mathrm{T})$ of the butyrophilin, subfamily 2, member A1 gene (5-7) was a susceptibility locus for dyslipidemia in Japanese individuals. However, the genetic variants, which confer susceptibility to dyslipidemia in Japanese individuals, remain to be elucidated.

Various loci and genes, which confer susceptibility to coronary heart disease (CHD), have been identified in Caucasian 
populations by meta-analyses of genome-wide association studies (GWAS) $(8,9)$. Considering that dyslipidemia is a major risk factor for CHD, it was hypothesized that certain polymorphisms may contribute to the genetic susceptibility to CHD through their effects on the susceptibility to dyslipidemia.

The aim of the present study was to examine a possible association of hypertriglyceridemia, hypo-high density lipoprotein (HDL)-cholesterolemia or hyper-low density lipoprotein (LDL)-cholesterolemia in Japanese individuals. This was performed with 29 polymorphisms identified as susceptibility loci for CHD by meta-analyses of GWAS in Caucasian populations $(8,9)$.

\section{Patients and methods}

Study population. The study population comprised 5,460 Japanese individuals who either visited outpatient clinics or were admitted to the participating hospitals (Gifu Prefectural General Medical Center, Gifu, Japan; Gifu Prefectural Tajimi Hospital, Tajimi, Japan; Japanese Red Cross Nagoya First Hospital, Nagoya, Japan; Inabe General Hospital, Inabe, Japan; Hirosaki University Hospital and Hirosaki Stroke Center, Hirosaki, Japan) between 2002 and 2012, as a result of various symptoms or for an annual health checkup. Venous blood was collected from the patients in the early morning following fasting overnight. Blood samples were centrifuged at $1,600 \mathrm{x} \mathrm{g}$ for $15 \mathrm{~min}$ at $4^{\circ} \mathrm{C}$, and the serum was separated and stored at $-30^{\circ} \mathrm{C}$ prior to analysis. Serum concentrations of triglycerides, HDL-cholesterol and LDL-cholesterol were measured using an automatic biochemical analyzer at a clinical laboratory in each hospital.

Hypertriglyceridemia was defined as a serum concentration of triglycerides of $>1.65 \mathrm{mmol} / \mathrm{l}(150 \mathrm{mg} / \mathrm{dl})$,hypo-HDL-cholesterolemia as a serum concentration of HDL-cholesterol of $<1.04 \mathrm{mmol} / \mathrm{l}(40 \mathrm{mg} / \mathrm{dl})$ and hyper-LDL-cholesterolemia as a serum concentration of LDL-cholesterol of $>3.63 \mathrm{mmol} / 1$ $(140 \mathrm{mg} / \mathrm{dl})$. Individuals with dyslipidemia either exhibited hypertriglyceridemia, hypo-HDL-cholesterolemia or hyper-LDL-cholesterolemia. The corresponding controls exhibited a serum triglyceride level of $<1.65 \mathrm{mmol} / 1$, a serum HDL-cholesterol of $\geq 1.04 \mathrm{mmol} / 1$ or a serum LDL-cholesterol of $<3.64 \mathrm{mmol} / 1$ in investigations of hypertriglyceridemia, hypo-HDL-cholesterolemia or hyper-LDL-cholesterolemia, respectively, and no history of taking antidyslipidemic medications.

The study protocol complied with the Helsinki Declaration of 1975 (as revised in 1983) and was approved by the Ethics Committees of each participating hospital. Written informed consent was obtained from all individuals involved in the present study.

Selection and genotyping of polymorphisms. Single nucleotide polymorphisms (SNPs), which have been revealed to be significantly associated with CHD or myocardial infarction in Caucasian populations in meta-analyses of GWAS data were searched $(8,9)$. The identified SNPs were examined using the SNP database (dbSNP; National Center for Biotechnology Information, Bethesda, MD, USA; http://www.ncbi.nlm.nih. gov/SNP) to identify SNPs with a minor allele frequency of $\geq 0.015$ in a Japanese population. A total of 29 SNPs were selected (data not shown) and the possible association with hypertriglyceridemia, hypo-HDL-cholesterolemia or hyper-LDL-cholesterolemia was investigated. Wild-type (ancestral allele) and variant alleles of the SNPs were determined from the original sources.

Venous blood $(7 \mathrm{ml})$ was collected into tubes, containing $50 \mathrm{mmol} / 1$ ethylenediaminetetraacetic acid (disodium salt) and the peripheral blood leukocytes were isolated. The genomic DNA was subsequently extracted from these cells using a DNA extraction kit (Genomix; Talent Srl, Trieste, Italy). The genotypes of the 29 polymorphisms were determined at G\&G Science Co., Ltd. (Fukushima, Japan) using a method, which combines polymerase chain reaction and sequence-specific oligonucleotide probes with suspension array technology (Luminex Corporation, Austin, TX, USA). The overall call rate of genotyping of 29 SNPs was $99 \%$. Detailed genotyping methodology was as described previously (10).

Statistical analysis. The $\chi^{2}$ test was used to compare categorical variables and the Mann-Whitney $U$ test was used for the analysis of quantitative data. The allele frequencies of each SNP were compared between the patients with hypertriglyceridemia, hypo-HDL-cholesterolemia or hyper-LDL-cholesterolemia, and the controls, using the $\chi^{2}$ test. To compensate for multiple comparisons of genotypes, a false discovery rate (FDR) was calculated from the distribution of P-values for the allele frequencies of 29 SNPs, and an FDR of $<0.05$ was considered to be statistically significant for the association. The statistical power of each SNP was calculated using an Online Sample Size Estimator (http://osse.bii.a-star. edu.sg/index.php). Multivariable logistic regression analysis was performed with hypertriglyceridemia, hypo-HDL-cholesterolemia or hyper-LDL-cholesterolemia as a dependent variable, and independent variables, including age, gender $(0$, female; 1 , male), body mass index (BMI) and the genotype of each SNP. Each SNP was assessed, according to dominant (the combined group of heterozygotes and variant homozygotes versus wild-type homozygotes), recessive (variant homozygotes versus the combined group of wild-type homozygotes and heterozygotes) and two additive [additive 1 (heterozygotes versus wild-type homozygotes) and additive 2 (variant homozygotes versus wild-type homozygotes)] genetic models. Considering that the serum concentrations of triglycerides, HDL-cholesterol, or LDL-cholesterol were not normally distributed $(\mathrm{P}<0.01$, according to the Kolmogorov-Smirnov and Lilliefors test), these parameters were compared among genotypes using the non-parametric Kruskal-Wallis test. Statistical analyses were performed with JMP version 11 and JMP Genomics version 6 software (SAS Institute Inc., Cary, NC, USA).

\section{Results}

Characteristics of the patients. The clinical characteristics of patients with hypertriglyceridemia, hypo-HDL-cholesterolemia or hyper-LDL-cholesterolemia, and the corresponding controls are presented in Tables I-III. In the investigation of hypertriglyceridemia, the frequency of males, BMI, the prevalence of smoking, diabetes mellitus, hypertension, the 
Table I. Characteristics of patients with hypertriglyceridemia and the corresponding controls.

\begin{tabular}{lccr}
\hline Characteristic & Hypertriglyceridemia & Controls & P-value \\
\hline No. of patients & 1,612 & 3,005 & \\
Age (years) & $63.6 \pm 10.3$ & $64.7 \pm 11.2$ & 0.0004 \\
Gender (male/female, \%) & $69.6 / 30.4$ & $60.0 / 40.0$ & $<0.0001$ \\
Body mass index $\left(\mathrm{kg} / \mathrm{m}^{2}\right)$ & $24.7 \pm 3.5$ & $23.4 \pm 3.4$ & $<0.0001$ \\
Current or former smoker $(\%)$ & 31.5 & 25.8 & $<0.0001$ \\
Diabetes mellitus $(\%)$ & 47.4 & 34.4 & $<0.0001$ \\
Hypertension $(\%)$ & 72.6 & 61.9 & $<0.0001$ \\
Serum triglycerides $(\mathrm{mmol} / \mathrm{l})$ & $2.63 \pm 1.31$ & $1.03 \pm 0.34$ & $<0.0001$ \\
Serum HDL-cholesterol $(\mathrm{mmol} / \mathrm{l})$ & $1.19 \pm 0.35$ & $1.40 \pm 0.42$ & $<0.0001$ \\
Serum LDL-cholesterol $(\mathrm{mmol} / \mathrm{l})$ & $3.21 \pm 1.02$ & $3.09 \pm 0.86$ & $<0.0001$ \\
Serum creatinine $(\mu \mathrm{mol} / \mathrm{l})$ & $92.9 \pm 101.7$ & $86.7 \pm 103.5$ & $<0.0001$ \\
eGFR (ml min $\left.{ }^{-1} 1.73 \mathrm{~m}^{-2}\right)$ & $66.1 \pm 25.2$ & $70.1 \pm 23.6$ & $<0.0001$ \\
Fasting plasma glucose $(\mathrm{mmol} / \mathrm{l})$ & $7.52 \pm 3.75$ & $6.63 \pm 3.00$ & $<0.0001$
\end{tabular}

Quantitative data are presented as the mean \pm standard deviation. HDL, high density lipoprotein; LDL, low density lipoprotein; eGFR, estimated glomerular filtration rate $\left(\mathrm{ml} \mathrm{min}^{-1} 1.73 \mathrm{~m}-2\right)=194 \times$ [age (years) $]^{-0.287} \mathrm{x}$ [serum creatinine $\left.(\mathrm{mg} / \mathrm{dl})\right]^{-1.094} \mathrm{x}[0.739$ if female] .

Table II. Characteristics of patients with hypo-HDL-cholesterolemia and the corresponding controls.

\begin{tabular}{|c|c|c|c|}
\hline Characteristic & Hypo-HDL-cholresterolemia & Controls & P-value \\
\hline No. of patients & 1,100 & 3,521 & \\
\hline Age (years) & $64.1 \pm 10.8$ & $64.3 \pm 11.0$ & 0.5742 \\
\hline Gender (male/female, \%) & $81.9 / 18.1$ & $57.2 / 42.8$ & $<0.0001$ \\
\hline Body mass index $\left(\mathrm{kg} / \mathrm{m}^{2}\right)$ & $24.4 \pm 3.5$ & $23.6 \pm 3.4$ & $<0.0001$ \\
\hline Current or former smoker $(\%)$ & 37.4 & 24.2 & $<0.0001$ \\
\hline Diabetes mellitus (\%) & 47.3 & 35.4 & $<0.0001$ \\
\hline Hypertension $(\%)$ & 71.6 & 63.5 & $<0.0001$ \\
\hline Serum triglycerides $(\mathrm{mmol} / \mathrm{l})$ & $1.89 \pm 1.42$ & $1.49 \pm 0.97$ & $<0.0001$ \\
\hline Serum HDL-cholesterol (mmol/l) & $0.88 \pm 0.12$ & $1.46 \pm 0.36$ & $<0.0001$ \\
\hline Serum LDL-cholesterol (mmol/l) & $3.06 \pm 0.95$ & $3.15 \pm 0.91$ & $<0.0001$ \\
\hline Serum creatinine $(\mu \mathrm{mol} / \mathrm{l})$ & $99.9 \pm 126.5$ & $84.9 \pm 94.6$ & $<0.0001$ \\
\hline eGFR $\left(\mathrm{ml} \mathrm{min} \min ^{-1} 1.73 \mathrm{~m}^{-2}\right)$ & $67.1 \pm 28.3$ & $69.2 \pm 22.7$ & 0.0008 \\
\hline Fasting plasma glucose (mmol/l) & $7.46 \pm 3.41$ & $6.77 \pm 3.27$ & $<0.0001$ \\
\hline
\end{tabular}

Quantitative data are presented as the mean \pm standard deviation. HDL, high density lipoprotein; LDL, low density lipoprotein; eGFR, estimated glomerular filtration rate.

serum concentrations of triglycerides, LDL-cholesterol and creatinine, and the fasting plasma glucose level were greater, whereas age, the serum concentrations of HDL-cholesterol and the estimated glomerular filtration rate (eGFR) were lower, in patients with hypertriglyceridemia compared with the controls (Table I). In the study of hypo-HDL-cholesterolemia, the frequency of males, BMI, the prevalence of smoking, diabetes mellitus, hypertension, the serum concentrations of triglycerides and creatinine, and the fasting plasma glucose level were greater, whereas the serum concentrations of LDL-cholesterol, HDL-cholesterol and eGFR were lower, in patients with hypo-HDL-cholesterolemia compared with the controls (Tables II). In the study of hyper-LDL-cholesterolemia, BMI, the serum concentrations of triglycerides and LDL-cholesterol, and the fasting plasma glucose level were greater, whereas age, the frequency of males and the serum concentrations of creatinine were lower, in patients with hyper-LDL-cholesterolemia compared with the controls (Table III).

Association of SNPS with hypertriglyceridemia, hypo-HDL-cholesterolemia or hyper-LDL-cholesterolemia. The allele frequencies were compared between the patients with hypertriglyceridemia, hypo-HDL-cholesterolemia (data not shown) or hyper-LDL-cholesterolemia and the corresponding controls using the $\chi^{2}$ test, and SNPs with an FDR of $<0.05$ are demonstrated in Table IV. The analysis revealed that rs964184 of zinc finger protein (ZPRI), rs4845625 of interleukin 6 receptor (IL6R), rs46522 of the ubiquitin-conjugating 
Table III. Characteristics of patients with hyper-LDL-cholesterolemia and the corresponding controls.

\begin{tabular}{lccr}
\hline Characteristic & Hyper-LDL-cholesterolemia & Controls & P-value \\
\hline No. of patients & 1,174 & 3,296 & 0.0135 \\
Age (years) & $63.7 \pm 10.7$ & $64.5 \pm 11.0$ & $<0.0001$ \\
Gender (male/female, $\%)$ & $57.4 / 42.6$ & $65.1 / 34.9$ & 0.0018 \\
Body mass index $\left(\mathrm{kg} / \mathrm{m}^{2}\right)$ & $24.1 \pm 3.5$ & $23.7 \pm 3.5$ & 0.1850 \\
Current or former smoker $(\%)$ & 26.4 & 28.4 & 0.2087 \\
Diabetes mellitus $(\%)$ & 40.0 & 38.0 & 0.1287 \\
Hypertension $(\%)$ & 67.3 & 64.8 & $<0.0001$ \\
Serum triglycerides $(\mathrm{mmol} / \mathrm{l})$ & $1.55 \pm 0.82$ & $1.50 \pm 0.91$ & 0.3301 \\
Serum HDL-cholesterol $(\mathrm{mmol} / \mathrm{l})$ & $1.31 \pm 0.36$ & $1.33 \pm 0.41$ & 0.0001 \\
Serum LDL-cholesterol $(\mathrm{mmol} / \mathrm{l})$ & $4.28 \pm 0.68$ & $2.72 \pm 0.59$ & 0.0026 \\
Serum creatinine $(\mu \mathrm{mol} / \mathrm{l})$ & $82.3 \pm 84.0$ & $92.0 \pm 110.6$ & 0.2490 \\
eGFR $\left(\mathrm{ml} \mathrm{min}{ }^{-1} 1.73 \mathrm{~m}^{-2}\right)$ & $69.6 \pm 23.4$ & $68.2 \pm 24.6$ & 0.0036 \\
Fasting plasma glucose $(\mathrm{mmol} / \mathrm{l})$ & $7.08 \pm 3.43$ & $6.81 \pm 3.17$ &
\end{tabular}

Quantitative data are presented as the mean \pm standard deviation. HDL, high density lipoprotein; LDL, low density lipoprotein; eGFR, estimated glomerular filtration rate.

enzyme E2Z (UBE2Z) and rs17514846 of furin (FURIN) were significantly associated with hypertriglyceridemia $(\mathrm{FDR}<0.05)$. Similar analysis revealed that rs599839 of proline/serine-rich coiled-coil 1 (PSRCl) and rs2075650 of translocase of outer mitochondrial membrane 40 homolog (TOMM40) were significantly associated with hyper-LDL-cholesterolemia. The statistical power of each SNP was calculated with the sample sizes and minor allele frequencies of cases and controls, and the significance level $(\alpha=0.05)$ was between 50.4 and $98.1 \%$. No SNPs significantly associated with hypo-HDL-cholesterolemia were identified (data not shown). The genotype distributions of six SNPs were in Hardy-Weinberg equilibrium (FDR $>0.05$ ) among patients with hypertriglyceridemia or hyper-LDL-cholesterolemia, and the controls.

Multivariable logistic regression analysis with adjustment for age, gender and BMI revealed that rs964184 of ZPRI (dominant, recessive, and additive 1 and 2 models), rs 4845625 of IL6R (dominant and additive 1 and 2 models) and rs46522 of UBE2Z (dominant and additive 1 models), however, not rs17514846 of FURIN, were significantly associated with hypertriglyceridemia (Table V). A similar analysis revealed that rs599839 of PSRCl (dominant and additive 1 models) and rs2075650 of TOMM40 (dominant and additive 1 and 2 models) were significantly associated with hyper-LDL-cholesterolemia.

Association of SNPs with serum concentrations of triglycerides or LDL-cholesterol. Finally, the association of the genotypes of each SNP with the serum concentrations of triglycerides or LDL-cholesterol were examined using the Kruskal-Wallis test (Table VI). The serum concentrations of triglycerides significantly differed among the genotypes of rs 964184 of ZPRI, rs 485625 of $I L 6 R$ and rs46522 of UBE2Z, with the minor G, $\mathrm{C}$ and $\mathrm{C}$ alleles, respectively, being associated with increased serum triglycerides. The rs17514846 of FURIN was also significantly associated with serum concentrations of triglycerides with the minor A allele being associated with reduced serum triglycerides. Serum concentrations of LDL-cholesterol also differed significantly among the genotypes of rs599839 of PSRC1 and rs2075650 of TOMM40. The minor G allele of rs599839 or the G allele of rs2075650 was associated with a reduced or increased concentration of serum LDL-cholesterol, respectively.

\section{Discussion}

The association between 29 SNPs and dyslipidemia was examined and it was observed that rs964184 of ZPR1, rs485625 of $I L 6 R$ and rs 46522 of UBE2Z were significantly associated with hypertriglyceridemia and that rs599839 of PSRC1 and rs2075650 of TOMM40 were associated with hyper-LDL-cholesterolemia.

The previous GWAS revealed that the $\mathrm{G}$ allele of rs 964184 of ZPRI was significantly associated with increased serum triglycerides and LDL-cholesterol, and with decreased serum HDL-cholesterol in European populations (11-14). The present study replicated the association of rs964184 with hypertriglyceridemia, however, not with hyper-LDL-cholesterolemia or hypo-HDL-cholesterolemia. The rs964184 of ZPRI is located in close proximity to the APOA5-A4-C3-A1 locus, which was revealed to be associated with plasma triglycerides in several previous studies with diverse populations, including Caucasian individuals $(15,16)$, Chinese individuals (17), individuals of Caucasian and African descent in the United States (18), and Middle Eastern populations (19). The expression of APOA5 is an efficient regulator of plasma triglycerides through its enhancement of the catabolism of triglyceride-rich lipoprotein (20) and prohibiting the transportation of triglycerides (21). The present results supported the findings of the previous investigations (11-19), that the genetic variant of $Z P R 1$ is important in the development of hypertriglyceridemia.

Consistent with previous GWAS investigating other ethnic groups $(22,23)$, an association between rs 4845625 of $I L 6 R$ with hypertriglyceridemia in Japanese individuals was observed. 
Table IV. Comparison of allele frequencies of SNPs $($ FDR $<0.05)$ using the $\chi^{2}$ test between patients with hypertriglyceridemia or hyper-LDL-cholesterolemia and controls.

A, Hypertriglyceridemia allele frequencies

\begin{tabular}{|c|c|c|c|c|c|}
\hline SNP & Hypertriglyceridemia $^{a}$ & Controls $^{\mathrm{a}}$ & $\begin{array}{c}\mathrm{P} \\
\text { (allele) }\end{array}$ & $\begin{array}{c}\text { FDR } \\
\text { (allele) }\end{array}$ & $\begin{array}{l}\text { Statistical } \\
\text { power }(\%)\end{array}$ \\
\hline rs964184 & & & $7.1 \times 10^{-9}$ & $2.1 \times 10^{-7}$ & 98.1 \\
\hline $\mathrm{CC}$ & $773(48.3)$ & $1,659(55.8)$ & & & \\
\hline $\mathrm{CG}$ & $672(42.0)$ & $1,136(38.2)$ & & & \\
\hline GG & $156(9.7)$ & $178(6.0)$ & & & \\
\hline $\mathrm{G}$ allele frequency & 0.31 & 0.25 & & & \\
\hline Hardy-Weinberg P & 0.5727 & 0.3699 & & & \\
\hline rs4845625 & & & 0.003 & 0.032 & 54.2 \\
\hline $\mathrm{TT}$ & $379(23.7)$ & $828(27.8)$ & & & \\
\hline $\mathrm{TC}$ & $820(51.2)$ & $1,475(49.5)$ & & & \\
\hline $\mathrm{CC}$ & $402(25.1)$ & $679(22.8)$ & & & \\
\hline $\mathrm{C}$ allele frequency & 0.51 & 0.48 & & & \\
\hline Hardy-Weinberg P & 0.3255 & 0.6521 & & & \\
\hline rs46522 & & & 0.001 & 0.032 & 57.1 \\
\hline $\mathrm{TT}$ & $850(53.1)$ & $1,729(58.2)$ & & & \\
\hline $\mathrm{TC}$ & $631(39.4)$ & $1,043(35.1)$ & & & \\
\hline $\mathrm{CC}$ & $119(7.4)$ & $200(6.7)$ & & & \\
\hline $\mathrm{C}$ allele frequency & 0.27 & 0.24 & & & \\
\hline Hardy-Weinberg P & 0.8988 & 0.0132 & & & \\
\hline rs17514846 & & & 0.006 & 0.041 & 50.4 \\
\hline $\mathrm{CC}$ & $1,175(73.8)$ & $2,067(70.2)$ & & & \\
\hline $\mathrm{CA}$ & $387(24.3)$ & $796(27.0)$ & & & \\
\hline AA & $31(2.0)$ & $82(2.8)$ & & & \\
\hline A allele frequency & 0.14 & 0.16 & & & \\
\hline Hardy-Weinberg P & 0.8949 & 0.6110 & & & \\
\hline
\end{tabular}

B, Hyper-LDL-cholesterolemia allele frequencies

\begin{tabular}{|c|c|c|c|c|c|}
\hline SNP & Hyper-LDL-cholesterolemia ${ }^{a}$ & Controls $^{\mathrm{a}}$ & $\begin{array}{c}\mathrm{P} \\
\text { (allele) }\end{array}$ & $\begin{array}{c}\text { FDR } \\
\text { (allele) }\end{array}$ & $\begin{array}{l}\text { Statistical } \\
\text { power }(\%)\end{array}$ \\
\hline rs599839 & & & 0.0003 & 0.004 & 77.4 \\
\hline AA & $1,023(88.4)$ & $2,729(84.1)$ & & & \\
\hline $\mathrm{AG}$ & $129(11.2)$ & $487(15.0)$ & & & \\
\hline GG & $5(0.4)$ & $29(0.9)$ & & & \\
\hline $\mathrm{G}$ allele frequency & 0.06 & 0.08 & & & \\
\hline Hardy-Weinberg P & 0.6674 & 0.1627 & & & \\
\hline rs2075650 & & & 0.0003 & 0.004 & 72.0 \\
\hline AA & $763(65.8)$ & $2,321(71.2)$ & & & \\
\hline $\mathrm{AG}$ & $351(30.3)$ & $848(26.0)$ & & & \\
\hline GG & $46(4.0)$ & $92(2.8)$ & & & \\
\hline $\mathrm{G}$ allele frequency & 0.19 & 0.16 & & & \\
\hline Hardy-Weinberg P & 0.4813 & 0.1735 & & & \\
\hline
\end{tabular}

${ }^{a}$ Numbers in parentheses are percentages. Allele frequencies of each SNP were compared between subjects with (A) hypertriglyceridemia or with (B) hyper-LDL-cholesterolemia and corresponding controls by the $\chi^{2}$ test and an FDR $<0.05$ was considered statistically significant. Call rate of genotyping was (A) $99.1 \%$ for rs $964184,99.3 \%$ for rs $4845625,99.0 \%$ for $46522,98.3 \%$ for 17514846 , (B) $98.5 \%$ for 599839 , or $98.9 \%$ for rs2075650. LDL, low density lipoprotein; FDR, false discovery rate; SNP, single nucleotide polymorphism.

IL6 binds to its receptor, initiating the intracellular cascade of the inflammatory response. In addition, IL6 has been reported to inhibit lipoprotein lipase activity and stimulate lipolysis, which lead to increased concentrations of serum triglycer- 
Table VI. Association between genotypes of SNPs and fasting serum concentrations of triglycerides or LDL-cholesterol as determined using the Kruskal-Wallis test.

\begin{tabular}{lcc} 
A, Triglycerides & & \\
\hline & Serum & \\
Genotype of SNP & concentration (mmol/l) & P-value \\
\hline rs964184 $(\mathrm{C} \rightarrow \mathrm{G})$ & & \\
CC & $1.49 \pm 1.03$ & \\
CG & $1.66 \pm 1.19^{\mathrm{a}}$ & \\
GG & $1.93 \pm 1.32^{\mathrm{a}}$ & $1.37 \times 10^{-12}$ \\
rs4845625 $(\mathrm{T} \rightarrow \mathrm{C})$ & & \\
TT & $1.52 \pm 1.02$ & \\
TC & $1.61 \pm 1.18^{\mathrm{a}}$ & \\
CC & $1.61 \pm 1.10^{\mathrm{a}}$ & 0.0273 \\
rs46522 $(\mathrm{T} \rightarrow \mathrm{C})$ & & \\
TT & $1.53 \pm 1.02$ & \\
TC & $1.68 \pm 1.27^{\mathrm{a}}$ & \\
CC & $1.61 \pm 1.06$ & \\
rs17514846 $(\mathrm{C} \rightarrow \mathrm{A})$ & & \\
CC & $1.61 \pm 1.16$ & \\
CA & $1.56 \pm 1.08$ & \\
AA & $1.37 \pm 0.77^{\mathrm{a}}$ & 0.0455 \\
\hline B, LDL-cholesterol & & \\
\hline & & \\
Genotype of SNP & concentration $(\mathrm{mmol} / \mathrm{l})$ & P-value \\
\hline rs599839 $(\mathrm{A} \rightarrow \mathrm{G})$ & & \\
AA & $3.15 \pm 0.93$ & \\
AG & $3.01 \pm 0.87^{\mathrm{a}}$ & \\
GG & $2.93 \pm 0.86$ & \\
rs2075650 $(\mathrm{A} \rightarrow \mathrm{G})$ & $3.09 \pm 0.90$ & \\
AA & $3.20 \pm 0.97^{\mathrm{a}}$ & \\
AG & & \\
GG & & \\
\hline aP-value of $<0.05$ vs. corresponding wild-type homozygotes. SNP, & \\
single nucleotide polymorphism; LDL, low density lipoprotein. \\
\hline
\end{tabular}

ides (24), suggesting that the IL6-IL6R cascades are crucial in the metabolism of triglycerides. Observations from previous studies $(22,23,25,26)$ and the present observations, therefore, demonstrated that rs 4845625 of IL6R is a susceptibility locus for increased serum triglycerides levels.

The rs46522 of $U B E 2 Z$ was significantly associated with hypertriglyceridemia. $U B E 2 Z$ is located at position $\mathrm{q} 21.32$ on chromosome 17 and encodes an enzyme, which ubiquitinates proteins involved in signaling pathways and apoptosis (27). Although the biological mechanism by which rs46522 of $U B E 2 Z$ modifies the serum triglyceride level remains to be elucidated, one possibility is the effect mediated by a 
polymorphism of the gastric inhibitory polypeptide gene, which is in linkage disequilibrium with the rs46522 (8) and was observed to affect plasma glucose and serum triglycerides levels (28).

The FURIN locus has been reported to be associated with hypertension (29) and formation of atherosclerotic plaques (30), however, not with hypertriglyceridemia. In the present study, logistic regression analysis with adjustment for covariates revealed no significant association between rs17514846 and hypertriglyceridemia. Although serum concentrations of triglycerides differed among genotypes of rs17514846 with a borderline significance, this SNP may not be a significant factor affecting the serum triglyceride levels.

Previous studies have demonstrated that rs599839 of PSRC1 is significantly associated with serum LDL-cholesterol levels, wherein the minor $G$ allele is associated with decreased serum LDL-cholesterol (31-35). The association of rs599839 with hyper-LDL-cholesterolemia with the $\mathrm{G}$ allele and its association with reduced LDL-cholesterol levels in a Japanese population was also assessed. The rs599839 of PSRC1 is located in the cadherin EGF LAG seven-pass G-type receptor 2 (CELSR2)-PSRC1-sortilin 1 (SORT1) gene cluster in position 13.3 on chromosome 1 . The primary role of CELSR2 or PSRC1 is contact-mediated cell adhesion (36) or microtubule destabilization (37), respectively, while SORT1 is important in lipid metabolism (38). SORT1, the higher expression of which is associated with the $G$ allele of rs599839, is a multi-ligand transmembrane receptor protein, which binds to a variety of ligands, including LDL-receptor-associated protein (39), lipoprotein lipase (40) and apolipoprotein A-V (41), and enhances the endocytosis and intracellular degradation of LDL-cholesterol. Considering that rs599839 is located in the 3'-untranslated region of PSCR1, which is downstream of SORT1, the effect of rs599839 on LDL-cholesterol may be mediated by an interaction with SORTI (42).

The rs2075650 of TOMM40 was also associated with serum concentrations of LDL-cholesterol. TOMM40 protein is localized to the mitochondrial outer membrane and is essential for the import and trafficking of proteins into the mitochondria (43). A genetic variant of TOMM40 was observed to be a risk factor for Alzheimer's disease through the increased deposition of $\beta$-amyloid (44). However, the underlying mechanism by which TOMM40 affects serum LDL-cholesterol levels remains to be elucidated. The rs2075650 is located in close proximity to the apolipoprotein E (APOE) locus. The SNPs of TOMM40 are in strong linkage disequilibrium with the $\mathrm{C}$ allele of rs429358 of APOE, which increases the plasma LDL-cholesterol levels $(45,46)$. Therefore, the effect of rs2075650 on LDL-cholesterol may be attributable to linkage disequilibrium with the polymorphism of $A P O E(47,48)$.

In conclusion, the present study indicated that rs964184 of ZPRI, rs4845625 of IL6R and rs46522 of UBE2Z were susceptibility loci for hypertriglyceridemia, and that rs599839 of PSRC1 and rs2075650 of TOMM40 were such loci for hyper-LDL-cholesterolemia in Japanese individuals. Further studies are required to confirm the present findings in other ethnic groups and to elucidate the functional relevance of these genes or SNPs to the pathogenesis of dyslipidemia.

\section{Acknowledgements}

This study was supported by a Collaborative Research Grant from the Gifu Prefectural General Medical Center (no. H24-26) and a Grant-in-Aid for Scientific Research from the Ministry of Education, Culture, Sports, Science, and Technology of Japan (no. 24590746).

\section{References}

1. Heller DA, de Faire U, Pedersen N, Dahlén G and McClearn GE: Genetic and environmental influences on serum lipid levels in twins. N Eng J Med 328: 1150-1156, 1993.

2. Pérusse L, Rice T, Després JP, Bergeron J, Province MA, Gagnon J, Leon AS, Rao DC, Skinner JS, Wilmore JH and Bouchard C: Familial resemblance of plasma lipids, lipoproteins and postheparin lipoprotein and hepatic lipase in the HERITAGE Family Study. Arterioscler Thromb Vasc Biol 17: 3263-3269, 1997.

3. Global Lipids Genetics Consortium, Willer CJ, Schmidt EM, Sengupta S, Peloso GM, Gustafsson S, Kanoni S, Ganna A, Chen J, Buchkovich ML, et al: Discovery and refinement of loci associated with lipid levels. Nat Genet 45: 1274-1283, 2013.

4. Kirillova OO: Modern concepts of gene polymorphism, which regulate lipid metabolism. Vopr Pitan 81: 48-52, 2012.

5. Fujimaki T, Kato K, Oguri M, Yohida T, Horibe H, Yokoi K, Watanabe S, Satoh K, Aoyagi Y, Tanaka M, et al: Association of polymorphism of BTN2A1 with dyslipidmemia in East Asian populations. Exp Ther Med 2: 745-749, 2011.

6. Horibe H, Ueyama C, Fujimaki T, Oguri M, Kato K, Ichihara S and Yamada Y: Association of a polymorphism of BTN2A1 with dyslipidemia in community-dwelling individuals. Mol Med Rep 9: 808-812, 2014.

7. Hiramatsu M, Oguri M, Kato K, Horibe H,Fujimaki T, Watanabe S, Satoh K, Aoyagi Y, Tanaka M, Shin DJ, et al: Synergistic effects of genetic variants of APOA5 and BTN2A1 on dyslipidemia or metabolic syndrome. Int J Mol Med 30: 185-192, 2012.

8. Schunkert H, König IR, Kathiresan S, Reilly MP, Assimes TL, Holm H, Preuss M, Stewart AF, Barbalic M, Gieger C, et al: Large-scale association analysis identifies 13 new susceptibility loci for coronary artery disease. Nat Genet 43: 333-338, 2011.

9. CARDIoGRAMplusC4D Consortium, Deloukas P, Kanoni S, Willenborg C, Farrall M, Assimes TL, Thompson JR, Ingelsson E, Saleheen D, Erdmann J, et al: Large-scale association analysis identifies new risk loci for coronary artery disease. Nat Genet 45: 25-33, 2013.

10. Itoh Y, Mizuki N, Shimada T, Azuma F, Itakura M, Kashiwase K, Kikkawa E, Kulski JK, Satake M and Inoko H: High-throughput DNA typing of HLA-A, -B, -C and -DRB1 loci by a PCR-SSOP-Luminex method in the Japanese population. Immunogenetics 57: 717-729, 2005.

11. Waterworth DM, Ricketts SL, Song K, Chen L, Zhao JH, Ripatti S, Aulchenko YS, Zhang W, Yuan X, Lim N, et al: Genetic variants influencing circulating lipid levels and risk of coronary artery disease. Arterioscler Thromb Vasc Biol 30: 2264-2276, 2010.

12. Teslovich TM, Musunuru K, Smith AV, Edmondson AC, Stylianou IM, Koseki M, Pirruccello JP, Ripatti S, Chasman DI, Willer CJ, et al: Biological, clinical and population relevance of 95 loci for blood lipids. Nature 466: 707-713, 2010.

13. Nakayama K, Yanagisawa Y, Ogawa A, Ishizuka Y, Munkhtulga L, Charupoonphol P, Supannnatas S, Kuartei S, Chimedregzen U, Koda $\mathrm{Y}$, et al: High prevalence of an anti-hypertriglyceridemic variant of the MLXIPL gene in Central Asia. J Hum Genet 56: 828-833, 2011.

14. Kathiresan S, Willer CJ, Peloso GM, Demissie S, Musunuru K, Schadt EE, Kaplan L, Bennett D, Li Y, Tanaka T, et al: Common variants at 30 loci contribute to polygenic dyslipidemia. Nat Genet 41: 56-65, 2009.

15. Kathiresan S, Melander O, Guiducci C, Surti A, Burtt NP, Rieder MJ, Cooper GM, Roos C, Voight BF, Havulinna AS, et al: Six new loci associated with blood low-density lipoprotein cholesterol, high-density lipoprotein cholesterol or triglycerides in humans. Nat Genet 40: 189-197, 2008.

16. Willer CJ, Sanna S, Jackson AU, Scuteri A, Bonnycastle LL, Clarke R, Heath SC, Timpson NJ, Najjar SS, Stringham HM, et al: Newly identified loci that influence lipid concentrations and risk of coronary artery disease. Nat Genet 40: 161-169, 2008. 
17. Yan SK, Cheng XQ, Song YH, Xiao XH, Bi N and Chen BS: Apolipoprotein A5 gene polymorphism -1131T- $>$ C: Association with plasma lipids and type 2 diabetes mellitus with coronary heart disease in Chinese. Clin Chem Lab Med 43: 607-612, 2005

18. Klos KL, Sing CF, Boerwinkle E, Hamon SC, Rea TJ, Clark A, Fornage $\mathrm{M}$ and Hixson JE: Consistent effects of genes involved in reverse cholesterol transport on plasma lipid and apolipoprotein levels in CARDIA participants. Arterioscler Thromb Vasc Biol 26: 1828-1836, 2006.

19. Ken-Dror G, Goldbourt U and Dankner R: Different effects of apolipoprotein A5 SNPs and haplotypes on triglyceride concentration in three ethnic origins. J Hum Genet 55: 300-307, 2010.

20. Jakel H, Nowak M, Helleboid-Chapman A, Fruchart-Najib J and Fruchart JC: Is apolipoprotein A5 a novel regulator of triglyceride-rich lipoproteins? Ann Med 38: 2-10, 2006.

21. Galernabi M, Lor K, Jin J, Chai F and Santanam N: The paradox of ApoA5 modulation of triglycerides: Evidence from clinical and basic research. Clin Biohem 46: 12-19, 2013

22. Vargas VR, Bonatto SL, Macagnan FE, Feoli AM, Alho CS Santos ND and Schmitt VM: Influence of the $48867 \mathrm{~A}>\mathrm{C}$ (Asp358Ala) IL6R polymorphism on response to a lifestyle modification intervention in individuals with metabolic syndrome. Genet Mol Res 12: 3893-3991, 2013.

23. Esteve E, Villuendas G, Mallolas J, Vendrell J, López-Bermejo A, Rodríguez M, Recasens M, Ricart W, San Millán JL, Escobar-Morreale $\mathrm{H}$, et al: Polymorphisms in the interleukin- 6 receptor gene are associated with body mass index and with characteristics of the metabolic syndrome. Clin Endocrinol (Oxf) 65: 88-91, 2006

24. Hardardóttir I, Grünfeld C and Feingold KR: Effects of endotoxin and cytokines on lipid metabolism. Curr Opin Lipidol 5: 207-215, 1994.

25. Chu NF, Lin FH, Chin HC and Hong YJ: Association between interleukin- 6 receptor gene variations and atherosclerotic lipid profiles among young adolescents in Taiwan. Lipids Health Dis 10: 136, 2011

26. Jiang CQ, Lam TH, Liu B, Lin JM, Yue XJ, Jin YL, Cheung BM and Thomas GN: Interleukin-6 receptor gene polymorphism modulates interleulin-6 levels and the metabolic syndrome: GBCS-CVD. Obesity (Silver Spring) 18: 1969-1974, 2010.

27. Gu X, Zhao F, Zheng M, Fei X, Chen X, Huang S, Xie Y and Mao Y: Cloning and characterization of a gene encoding the human putative ubiquitin conjugating enzyme E2Z (UBE2Z). Mol Biol Rep 34: 183-188, 2007.

28. Alssema M, Rijkelijkhuizen JM, Holst JJ, Teerlink T, Scheffer PG, Eekhoff EM, Gastaldelli A, Mari A, Hart LM, Nijpels G, et al: Preserved GLP-1 and exaggerated GIP secretion in type 2 diabetes and relationships with triglycerides and ALT. Eur J Endocrinol 169: 421-430, 2013.

29. International Consortium for Blood Pressure Genome-Wide Association Studies, Ehret GB, Munroe PB, Rice KM, Bochud M, Johnson AD, Chasman DI, Smith AV, Tobin MD Verwoert GC, et al: Genetic variants in novel pathways influence blood pressure and cardiovascular disease risk. Nature 478: 103-109, 2011.

30. Turpeinen H, Raitoharju E, Oksanen A, Oksala N, Levula M, Lyytikäinen LP, Järvinen $\mathrm{O}$, Creemers JW, Kähönen M, Laaksonen R, et al: Proprotein convertases in human atherosclerotic plaques: The overexpression of FURIN and its substrate cytokines BAFF and APRIL. Atherosclerosis 219: 799-806, 2011.

31. Samani NJ, Braund PS, Erdmann J, Götz A, Tomaszewski M, Linsel-Nitschke P, Hajat C, Mangino M, Hengstenberg C, Stark K, et al: The novel genetic variant predisposing to coronary artery disease in the region of the PSRC1 and CELSR2 genes on chromosome 1 associates with serum cholesterol. J Mol Med (Berl) 86: 1233-1241, 2008

32. Samani NJ, Erdmann J, Hall AS, Hengstenberg C, Mangino M, Mayer B, Dixon RJ, Meitinger T, Braund P, Wichmann HE, et al Genomewide association analysis of coronary artery disease. N Engl J Med 357: 443-453, 2007.
33. Kleber ME, Renner W, Grammer TB, Linsel-Nitschke P, Boehm BO, Winkelmann BR, Bugert P, Hoffmann MM and März W: Association of the single nucleotide polymorphism rs599839 in the vicinity of the sortilin 1 gene with LDL and triglyceride metabolism, coronary heart disease and myocardial infarction: The ludwigshafen risk and cardiovascular health study. Atherosclerosis 209: 492-497, 2010.

34. Muendlein A, Geller-Rhomberg S, Saely CH, Winder T, Sonderegger G, Rein P, Beer S, Vonbank A and Drexel H: Significant impact of chromosomal locus 1p13.3 on serum LDL cholesterol and on angiographically characterized coronary atherosclerosis. Atherosclerosis 206: 494-499, 2009.

35. Wang AZ, Li L, Zhang B, Shen GQ and Wang QK: Association of SNP rs17465637 on chromosome 1q451 and rs599839 on 1p13.3 with myocardial infarction in an American caucasian population. Ann Hum Genet 75: 475-482, 2011

36. Vincent JB, Skaug J and Scherer SW: The human homologue of flamingo, EGFL2, encode a brain-expressed large cadherin-like protein which epidermal growth factor-like domains and maps to chromosome 1p13.3-p21.1. DNA Res 7: 233-235, 2000.

37. Hsieh PC, Chang JC, Sun WT, Hsieh SC, Wang MC and Wang FF: p53 down-stream target DDA3 is a novel microtubule-associated protein that interacts with end-binding protein EB3 and activates beta-catenin pathway. Oncogene 26: 4928-4940, 2007.

38. Strong A and Rader DJ: Sortilin as a regulator of lipoprotein metabolism. Curr Atheroscler Rep 14: 211-218, 2012.

39. Jansen P, Giehl K, Nyengaard JR, Teng K, Lioubinski O, Sjoegaard SS, Breiderhoff T, Gotthardt M, Lin F, Eilers A, et al: Roles for the pro-neurotrophin receptor sortilin in neuronal development, aging and brain injury. Nat Neurosci 10: 1449-1457, 2007.

40. Nielsen MS, Jacobsen C, Olivecrona G, Gliemann J and Petersen CM: Sortilin/neurotensin receptor-3 binds and mediates degradation of lipoprotein lipase. J Biol Chem 274: 8832-8836, 1999.

41. Nilsson SK, Christensen S, Raarup MK, Ryan RO, Nielsen MS and Olivecrona G: Endocytosis of apolipoprotein A-V by members of the low density lipoprotein receptor and the VPS10p domain receptor families. J Biol Chem 283: 25920-25927, 2008.

42. Arvind P, Nair J, Jambunathan S, Kakkar VV and Shanker J: CELSR2-PSCR1-SORT1 gene expression and association with coronary artery disease and plasma lipid levels in an Asian Indian cohort. J Cardiol 64: 339-346, 2014.

43. Humphries AD, Streimann IC, Stojanovski D, Johnston AJ, Yano M, Hoogenraad NJ and Ryan MT: Dissection of the mitochondrial import and assembly pathway for human Tom40. J Biol Chem 280: 11535-11543, 2005

44. Cruchaga C, Nowotny P, Kauwe JS, Ridge PG, Mayo K, Bertelsen S, Hinrichs A, Fagan AM, Holtzman DM, Morris JC, et al: Association and expression analyses with single-nucleotide polymorphisms in TOMM40 in Alzheimer disease. Arch Neurol 68: 1013-1019, 2011.

45. Yu CE, Seltman H, Peskind ER, Galloway N, Zhou PX, Rosenthal E, Wijsman EM, Tsuang DW, Devlin B and Schellenberg GD: Comprehensive analysis of APOE and selected proximate markers for late-onset Alzheimer disease: Pattern of linkage disequilibrium and disease/marker association. Genomics 89: 655-665, 2007.

46. Bennet AM, Di Angelantonio E, Ye Z, Wensley F, Dahlin A, Ahlbom A, Keavney B, Collins R, Wiman B, de Faire U, et al: Association of apolipoprotein $\mathrm{E}$ genotypes with lipid levels and coronary risk. JAMA 298: 1300-1311, 2007.

47. Deelen J, Beekman M, Uh HW, Helmer Q, Kuningas M, Christiansen L, Kremer D, van der Breggen R, Suchiman HE, et al: Genome-wide association study identifies a single major locus contributing to survival into old age; the APOE locus revisited. Aging Cell 10: 686-698, 2011.

48. Nebel A, Kleindorp R, Caliebe A, Nothnagel M, Blanché H, Junge O, Wittig M, Ellinghaus D, Flachsbart F, Wichmann HE, et al: A genome-wide association study confirms APOE as the major gene influencing survival in long-lived individuals. Mech Ageing Dev 132: 324-330, 2011. 